\title{
VARIAÇÃO TEMPORAL DO ÍNDICE DE VEGETAÇÃO POR DIFERENÇA NORMALIZADA (NDVI) NO PARQUE NACIONAL DA RESTINGA DE JURUBATIBA
}

\author{
Saulo de Oliveira Folharini ${ }^{(a)}$, André Luiz dos Santos Furtado ${ }^{(b)}$ Regina Célia de Oliveira ${ }^{(c)}$ \\ (a) Departamento de Geografia/Universidade Estadual de Campinas, Email: $\underline{\text { ffolharini@gmail.com; }}$ \\ (b) Empresa Brasileira de Pesquisas Agropecuárias, Email: andre.furtado@embrapa.br; \\ (c) Departamento de Geografia/Universidade Estadual de Campinas, Email: reginacoliveira@ige.unicamp.br
}

\section{Eixo: GEOTECNOLOGIAS E MODELAGEM ESPACIAL EM GEOGRAFIA FÍSICA}

\begin{abstract}
Resumo
O objetivo deste estudo foi analisar a variação temporal do índice de vegetação por diferença normalizada (NDVI) no Parque Nacional da Restinga de Jurubatiba utilizando imagens do sistema/sensor Landsat-5/TM. Para tanto, a pesquisa foi estruturada em três etapas principais: aquisição das imagens, correção atmosférica e reprojeção, extração dos índices de vegetação. Os resultados apresentados neste estudo confirmam o predomínio de vegetação natural densa nas áreas próximas aos cursos d'água, locais possíveis de observar elevados NDVI, e de vegetação de densidade média na área de restinga no Parque Nacional da Restinga de Jurubatiba.
\end{abstract}

Palavras chave: índices de vegetação, sensoriamento remoto, Landsat-5/TM.

\section{Introdução}

O monitoramento e mapeamento de recursos naturais é realizado, na atualidade, utilizando amplamente as técnicas e ferramentas de sensoriamento remoto e imagens de satélite. Esses procedimentos e materiais possibilitam análises em escalas temporais e espaciais diversas, que resultam em estudos de diagnóstico importantes sobre a dinâmica da paisagem.

Classificar e quantificar a cobertura vegetal é uma forma de se obter uma visão espacial da distribuição das espécies existentes e ao analisar essa cobertura vegetal de forma temporal é possível obter por quais as variações ela passou. O resultado obtido pode ser devido a fatores ambientais, como a variação de temperatura e umidade causada pelas mudanças sazonais do clima ou devido a fatores humanos, como a expansão de áreas urbanas, que suprimem a vegetação natural.

Utilizando imagens de satélite em estudos de dinâmica sazonal, devido a fatores ambientais, é possível calcular os índices de vegetação, que são medidas radiométricas indicativas da atividade fotossintética da vegetação, a porcentagem de cobertura verde, biomassa verde, teor de clorofila (JENSEN, 2009). 
Entre os índices de vegetação conhecidos destaca-se o índice de vegetação por diferença normalizada (Normalized Difference Vegetation Index, NDVI), desenvolvido e proposto por Rouse et al. (1974), é calculado utilizando a reflectância do infravermelho próximo, quando a radiação é refletida em decorrência do espalhamento interno das células da planta, e a reflectância do vermelho, quando a radiação é absorvida pelos pigmentos que realizam a fotossíntese (PONZONI; SHIMABUKURO; KUPLICH, 2012).

O NDVI tem sido empregado em estudos que visam investigar a atividade fotossintética de culturas agrícolas e da vegetação natural, mapear uso e cobertura do solo, desmatamentos florestais, mudanças climáticas, entre outros. Nesse contexto, a presente pesquisa propõe a análise temporal do NDVI no Parque Nacional da Restinga de Jurubatiba e de sua zona de amortecimento.

\section{Metodologia}

\subsection{Area de estudo}

A área de estudo está localizada no litoral norte do Estado do Rio de Janeiro, entre as coordenadas geográficas $22^{\circ} 00^{\prime}$ e $22^{\circ} 23^{\prime} \mathrm{S}$ e $41^{\circ} 15^{\prime}$ e $41^{\circ} 45^{\prime} \mathrm{O}$. Sua área é de aproximadamente $149,22 \mathrm{~km}^{2}$ com cerca de $4 \mathrm{~km}$ de largura e $44 \mathrm{~km}$ de extensão e sua zona de amortecimento terrestre é de $386,28 \mathrm{~km}^{2}$. Abrange os municípios de Macaé, Quissamã e Carapebus, que possuem respectivamente, 206.728, 20.242 e 13.359 habitantes (IBGE, 2010). 


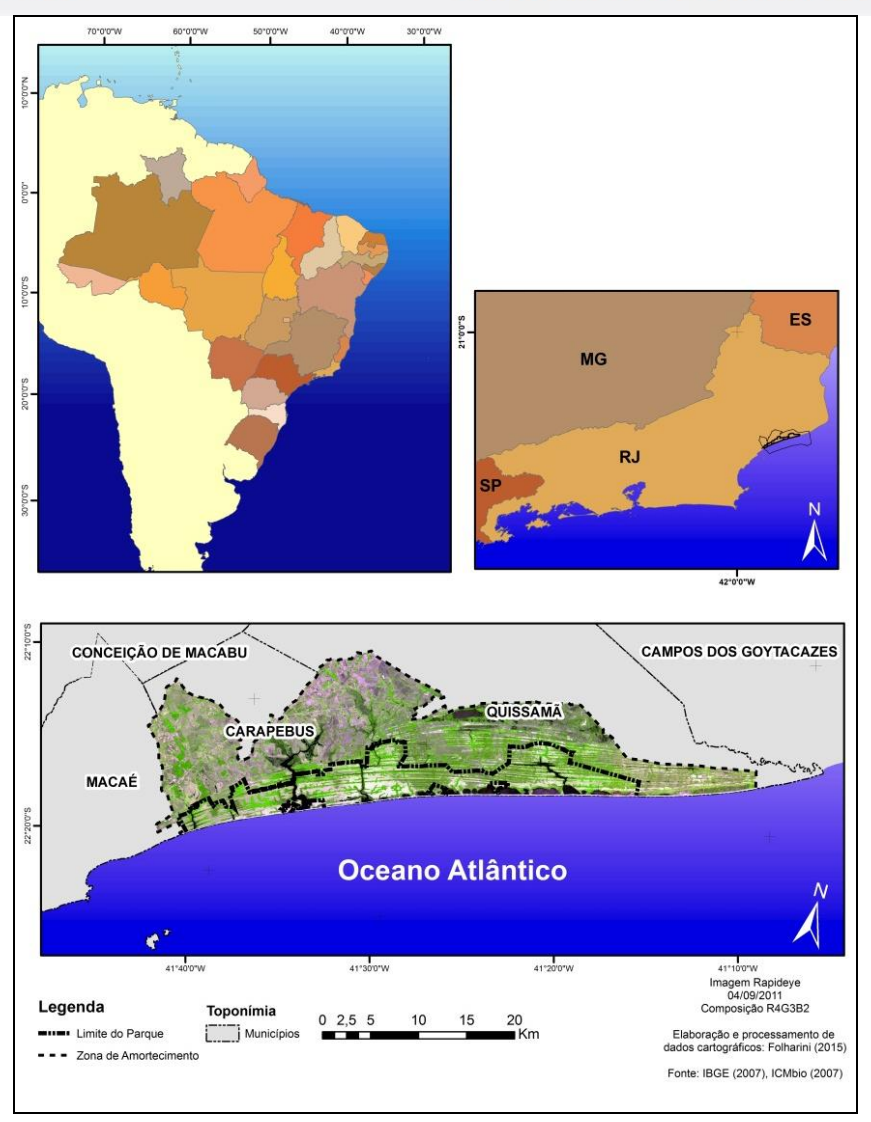

Figura 1: Localização da área de estudo.

Criado em 29 de abril de 1998, é administrado pelo ICMBio e está sujeito a diversos tipos de ação antrópica, por exemplo: atividades agrícolas, caça e pesca irregulares, queimadas e loteamentos devido sua localização próxima a áreas urbanas.

\subsection{Cálculo do Índice de Vegetação por Diferença Normalizada (NDVI)}

O cálculo do NDVI foi elaborado em imagens Landsat-5/TM, órbita/ponto: 216/75, adquiridas gratuitamente na página do United States Geological Survey (USGS, 2015), nas seguintes datas (tabela I):

\begin{tabular}{|c|c|}
\hline \multicolumn{2}{|c|}{ Tabela I: Informações das imagens } \\
\hline ID da imagem & Data da imagem \\
\hline LT52160751996017CUB00 & $17 / 01 / 1996$ \\
\hline LT52160752001046CUB00 & $15 / 02 / 2001$ \\
\hline LT52160752005009CUB00 & $09 / 01 / 2005$ \\
\hline LT52160752011042CUB00 & $11 / 02 / 2011$ \\
\hline
\end{tabular}


A escolha destas datas se justifica devido à possibilidade de realizar uma análise temporal que mostre $o$ cenário de cobertura vegetal antes e depois da criação do PARNA

Para o cálculo do NDVI seguiu-se algumas etapas básicas para o processamento, que estão estabelecidas abaixo (Fluxograma 1):

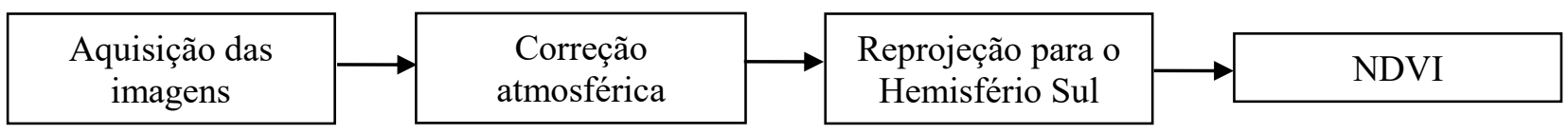

Fluxograma 1: Etapas do processamento.

Após o download das imagens, foi realizada a correção atmosférica utilizando o método $\operatorname{Cos}(\mathrm{t})$, desenvolvido por Chavez Júnior (1996), que incorpora todos os elementos da correção pelo pixel escuro (Dark Object Subtraction, DOS) com o auxílio do software Idrisi.

Essa técnica de aproximação considera tanto o efeito do espalhamento atmosférico quanto o da absorção atmosférica com base no cosseno do ângulo solar zenital. Primeiramente, os números digitais da imagem são convertidos para valores de radiância. A seguir, a radiância é convertida para reflectância. O resultado desse processamento gera uma imagem com valores de reflectância entre 0 e 1 .

Com o término da correção atmosférica foi realizada a reprojeção para o Hemisfério Sul, etapa necessária porque estas imagens são projetadas no sistema de coordenadas WGS-84, Hemisfério Norte, considerando as bandas 1, 2, 3, 4, 5 e 7, todas com resolução espacial de $30 \mathrm{~m}$. A banda 6 foi descartada, pois a sua resolução espacial é de $120 \mathrm{~m}$.

Após a reprojeção das imagens a área do Parque Nacional da Restinga de Jurubatiba na imagem Landsat foi recortada com o auxílio da ferramenta Subset data via ROI, disponível no software ENVI, e, em seguida, foi feito o cálculo do NDVI (ROUSE et al., 1974).

Para o cálculo do NDVI são empregadas as bandas do vermelho (V), utilizada pela vegetação durante o processo de fotossíntese, e do infravermelho próximo (IVP), refletida durante o mesmo processo. O índice é calculado com base na relação entre o vermelho e o infravermelho próximo (Fórmula 1):

$$
\mathrm{NDVI}=[(\rho \mathrm{IVP}-\rho \mathrm{V}) /(\rho \mathrm{IVP}+\rho \mathrm{V})]
$$

Foram definidas cinco classes de NDVI, através do classificador manual do ArcGIS, versão 10.3 e calculadas, em quilômetros, as áreas ocupadas por elas em cada imagem. 


\section{Resultados}

$\mathrm{O}$ resultado com as áreas em $\mathrm{km}^{2}$ do NDVI são apresentadas na Tabela II e na figura 2 é observada a distribuição espacial do índice:

Tabela II: Variação temporal dos valores de NDVI de 1996 a 2011.

\begin{tabular}{|c|c|c|c|c|c|c|c|c|}
\hline \multirow{2}{*}{ NDVI } & \multicolumn{2}{|c|}{$17 / 01 / 1996$} & \multicolumn{2}{|c|}{$15 / 02 / 2001$} & \multicolumn{2}{|c|}{$09 / 01 / 2005$} & \multicolumn{2}{|c|}{$11 / 02 / 2011$} \\
\hline & (km) & $\%$ & $(\mathbf{k m})$ & $\%$ & (km) & $\%$ & $(\mathbf{k m})$ & $\%$ \\
\hline$\leq 0,2$ & 29,34 & 5,48 & 51,14 & 9,55 & 30,04 & 5,61 & 15,74 & 2,94 \\
\hline $0,2-0,4$ & 90,32 & 16,87 & 200,79 & 37,50 & 101,82 & 19,02 & 106,33 & 19,86 \\
\hline $0,4-0,6$ & 175,44 & 32,76 & 203,99 & 38,10 & 177,61 & 33,17 & 246,99 & 46,13 \\
\hline 0,6 - 0,8 & 221,37 & 41,34 & 73,24 & 13,68 & 196,14 & 36,63 & 127,46 & 23,80 \\
\hline $0,8-1$ & 19,01 & 3,55 & 6,28 & 1,17 & 29,84 & 5,57 & 38,96 & 7,28 \\
\hline TOTAL & $\mathbf{5 3 5 , 5}$ & 100,00 & 535,5 & 100,00 & 535,5 & 100,00 & 535,5 & 100,00 \\
\hline
\end{tabular}
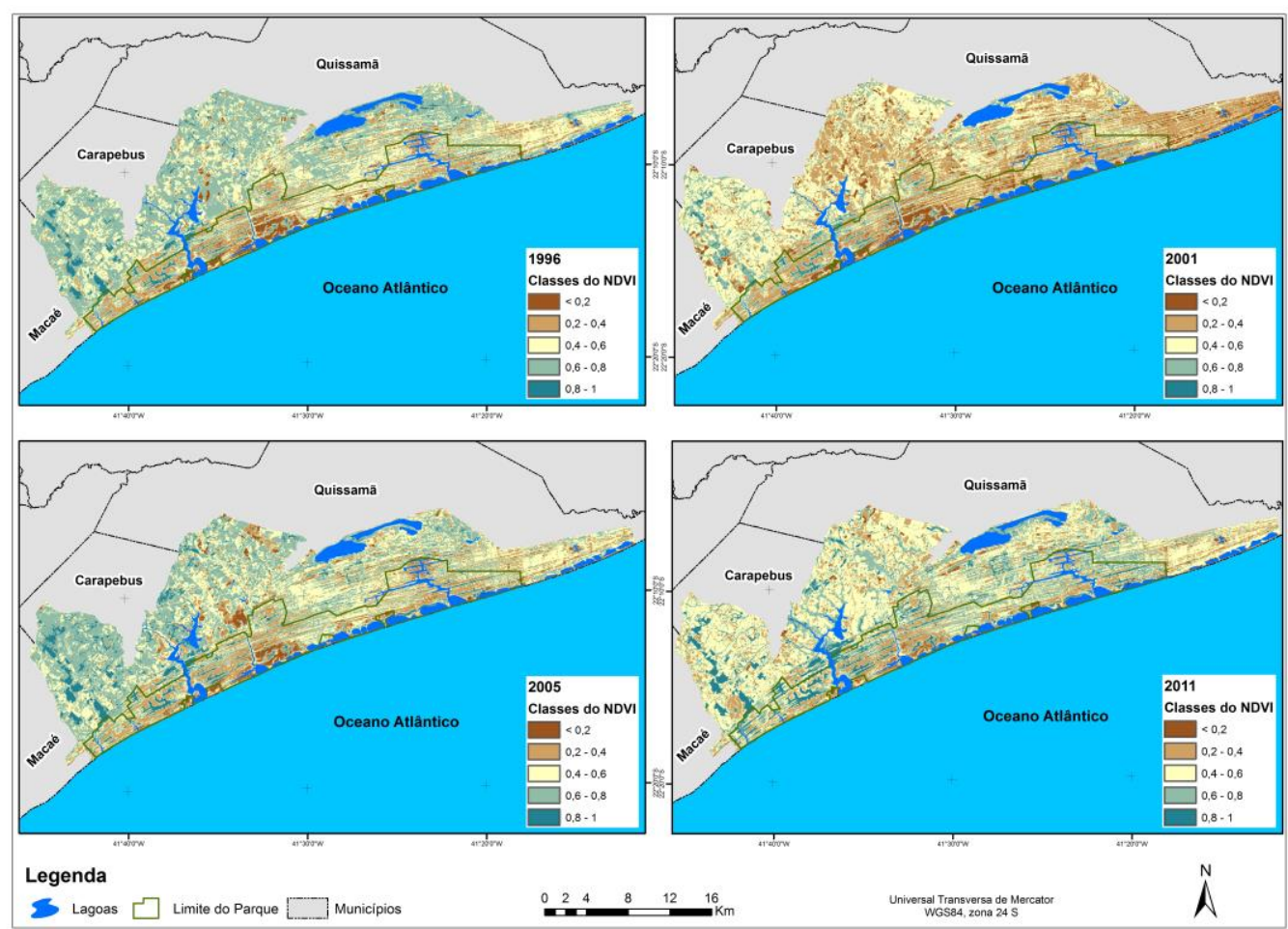

Figura 2: Variação temporal do NDVI.

O intervalo de valores entre 0,4 e 0,6 foi o que teve maior aumento no período analisado, seguido pelo intervalo de 0,8 a 1 . Já o intervalo de 0,6 a 0,8 é o que mais oscilou. $O$ intervalo de 0,2 a 0,4 apresentou um pequeno aumento em comparação com os outros intervalos. O intervalo $<0,2$ diminuiu. 
A variação desses dados mostra que houve aumento da área foliar, e consequentemente de biomassa, captado pelo NDVI, no período de 1996 a 2001. Esse resultado pode ser relacionado à criação do parque nacional (PARNA) em 1998, que limitou a expansão urbana e de agricultura na área de restinga.

Por sua vez, a diminuição da área de valores abaixo de 0,2 indicou que a ocorrência de solo exposto diminuiu, ou seja, houve aumento da biomassa da vegetação de restinga. Os valores baixos e médios mostram que a vegetação não é muito densa, característica marcante da vegetação de restinga que se distribui esparsamente pela área.

Já as áreas no intervalo de 0,8 a 1 diminuíram no primeiro momento, mas aumentaram no período. Essas áreas estão relacionadas a locais com alta concentração de área foliar e biomassa, indicam vegetação densa e ocorrem com maior frequência às margens das lagoas costeiras, justamente onde a presença de água auxilia no desenvolvimento da vegetação.

\section{Considerações Finais}

Os resultados apresentados confirmam o predomínio, no Parque Nacional da Restinga de Jurubatiba, da vegetação natural, com NDVI entre 0,4 e 0,8 , característica que se relaciona à vegetação de restinga, que tem por padrão distribuir-se pelo espaço de maneira esparsa.

A aplicação do NDVI nessa análise temporal permite concluir que há um padrão de área total do NDVI nos intervalos $<0,2 ; 0,4-0,6 ;>0,8$, com pequenas variações percentuais. Já os intervalos $0,2-0,4$ e 0,6 - 0,8 tiveram variações altas em comparação com os outros intervalos, o que pode ser um indicativo da variação sazonal da precipitação nas datas analisadas.

Esse cenário indica que a composição vegetal da área estudada alterou-se pouco no período analisado, com um indicativo positivo, que é o aumento de valores de NDVI $>0,8$, ou seja, a alta concentração de biomassa.

\section{Bibliografia}

CHAVEZ JÚNIOR, P. S. Image-based atmospheric corrections - revisited and improved. Photogrammetric Engineering and Remote Sensing, v. 62, p. 1025-1036, 1996.

IBGE. Censo Demográfico. 2010. Disponível em <http://censo2010.ibge.gov.br/ >, acessado em 14 fev 2016. 


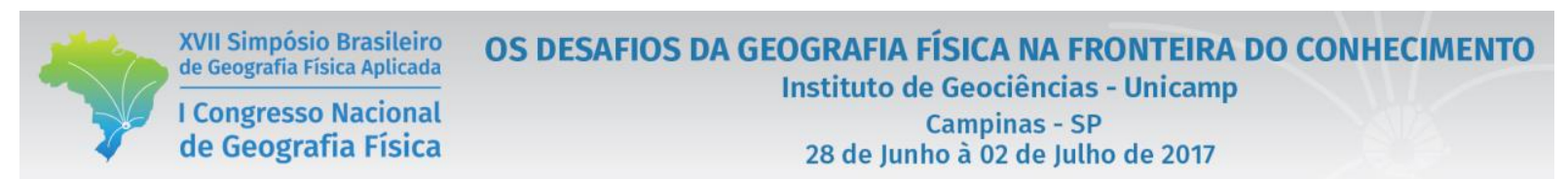

JENSEN, J. R. Sensoriamento remoto do ambiente: uma perspectiva em recursos terrestres. São José dos Campos: Parêntese, 2009.

PONZONI, F. J.; SHIMABUKURO, Y. E.; KUPLICH, T. M. Sensoriamento remoto da vegetação. 2 ed. São Paulo: Oficina de Textos, 2012.

ROUSE, J. W; HAAS, R. H.; SCHELL, J. A.; DEERING, D. W. Monitoring vegetation systems in the Great Plains with ERTS. In: FREDEN, S. C.; MERCANTI, E. P.; BECKER, M. (Eds.). . Third Earth Resources Technology Satellite - 1 Syposium. Volume I: Technical Presentations, NASA SP-351. Washington, D.C.: 1974. p. 309-317.

USGS - United States Geological Survey. Catálogo de Imagens Landsat. 2015. Disponível em <http://earthexplorer.usgs.gov>, acesso em 30 fev 2015. 